\title{
Culture and Negotiation
}

\author{
Jeanne M. Brett and Susan Crotty \\ Management and Organizations \\ Kellogg School of Management
}

Northwestern University

Evanston, IL 60208

jmbrett@kellogg.northwestern.edu

susancrotty@kellogg.northwestern.edu

March 1, 2007

In P. B. Smith, M. F. Peterson, \& D.C. Thomas (Eds.), Handbook of Cross-Cultural Management Research forthcoming from Sage. 
Negotiation theory and research has proliferated over the past 25 years; however, much of what we know is based on research using samples from the United States and Northern Europe and is laden with values and assumptions that are Western (Brett \& Gelfand, 2006). Research on culture and negotiation has evolved much more slowly. That evolution began with some rich descriptions of negotiations within a culture, for example, The Japanese Negotiator by Robert March (1988), and Chinese Business Negotiating Style by Tony Fang (1999). The evolution moved to comparative descriptions of national styles of negotiating such as Graham's (1985) “The Influence of Culture on Business Negotiations.”

Current research is following two trends in explaining culture's effects on negotiation. One trend uses the cultural dimensions approach. The research following this trend conceptualizes culture as a main effect and suggests that cultural effects are due to a variety of cultural dimensions of values, norms, and even institutional ideologies. The second trend is the constructivist approach. The research following this trend conceptualizes culture as interacting with context or individual differences or both to activate knowledge structures that direct negotiation behavior. In this chapter we will focus on reviewing the state of theory and research associated with both of these approaches, and then develop some suggestions for future research. We begin with definitions of culture and negotiation.

Culture is the distinct character of a social group (Lytle, Brett, Barsness, Tinsley, \& Janssens, 1995). Culture is manifest in the group's shared values, beliefs, norms. It is visible in the pattern of behaviors that are typical of group members when they respond to a problem of social interaction (Smith, Dugan, \& Trompenaars, 1996). Social, 
political, and economic institutions carry culture in their ideologies (Brett, 2001).

Cultural institutions also serve to socialize cultural members by rewarding and sanctioning behavior. Culture provides a basis for interpreting social situations and organizing and structuring social interaction (Brett \& Gelfand, 2006).

Negotiation is a process of decision making by which people who have conflicting interests determine how they are going to allocate resources, or work together in the future. Interests are the concerns, needs, fears, desires underlying negotiators' conflicting positions (Fisher, Ury, \& Patton, 1991). Negotiators are interdependent, which means what one wants affects what the other can have and vice versa.

Since negotiation is a form of social interaction and culture provides ways to handle problems of social interaction, it is reasonable to expect that culture will have an impact on negotiation. Brett (2001) suggests three ways culture can impact negotiations. Negotiators from different cultures may come to the negotiating table with interests and priorities that are culturally based and therefore different, which generates opportunities to create value through trade-offs. Culture may also affect negotiators' strategic behavior: their confrontational style, their social motives, and their use of integrative or distributive strategic approaches to negotiation. Cultural differences in negotiation strategy may keep negotiators from creating value or even reaching agreement. Culture also affects the environment in which negotiations occur. In same-culture negotiations the social, political, and economic environments are the same for both parties, even if these environments are not particularly stable. In cross-cultural negotiations, differences in negotiators' home culture's social, political, and economic environments may not only have a direct effect on negotiators' interests, priorities, and strategies, but an interactive 
effect with other situational factors that together with culture affect negotiation behaviors and outcomes.

\section{The Dimensional Approach to Studying Cultural Effects on Negotiations}

The dimensional approach to studying culture's effects on cultural members' behaviors really comprises two approaches depending on the conceptualization of culture: at the level of individual members of the culture or at the level of the national culture. At the individual or entity trait level, we find research that measures individuals' cultural values and utilizes differences in values to explain variation in negotiation behaviors and outcomes. At the level of the cultural group, researchers typically use previous research documenting cultural values to explain national culture differences in negotiation behaviors and outcomes. There are problems with both levels of conceptualization, as we shall document in subsequent paragraphs, but first we explain why negotiation researchers tend to distinguish cultures in terms of nation states.

There is an excellent reason for using national borders to define cultures in negotiation research despite the obvious point that there are many distinct cultural groups within national boundaries. The reason is that nation states define social, political, and economic boundaries (among others) that are fixed in same-culture negotiations but that vary when research is comparing negotiations across cultures or focused on inter-cultural negotiations. The ideology underlying a nation's social, political, and economic institutions is reflected in and reflects cultural values, beliefs, and norms (Brett, 2001). Thus, national boundaries provide appropriate distinctions for studying the psychology of cultures' effects on negotiations.

The Individual or Entity/Trait Approach 
Since the publication of Hofstede's (1980) influential Culture's Consequences cultural researchers in psychology have used Hofstede and others' measures of cultural values to explain behavior in a variety of domains. (See Peterson \& Wood, Chapter 3) There are two somewhat different types of studies that use cultural values to explain differences in negotiators' behaviors: studies that directly measure negotiators' cultural values and studies that use national cultural differences observed by others (e.g., Hofstede or Schwartz (1994), but that do not use measures of negotiators' cultural values in their hypotheses. We review studies using direct measurement of cultural values first, and then turn to studies that rely on national cultural differences observed by others.

An example of this direct measurement individual-level cultural research is Leung's (Leung, 1988) study comparing U.S. and Hong Kong participants' preferences for conflict resolution styles. Using Hui's (1984) 21-item collectivism scale, Leung found that Hong Kong participants were more collectivist than U.S. participants, showed that Hong Kong participants preferred bargaining and mediation more than U.S. participants, and that these preferences were correlated with perceptions that these techniques would lead to reduction of animosity between disputants. The analysis was correlational, however; Leung did not test mediation formally.

In another example, Gabrielidis, Stephan, Ybarra, Dos Santos Pearson, \& Villareal (1997) found that Mexican college students who scored higher on Hofstede's measure of collectivism and lower on feminism than U.S. college students demonstrated greater concern for others' outcomes in conflict resolution than did U.S. students. Mexican students also were more likely than U.S. students to prefer styles of conflict resolution that demonstrated a higher concern for others' outcomes - accommodation and 
collaboration than U.S. students. Gabrielidis et al. conducted a series of analyses of variance and within-country correlational analyses, but did not test mediation.

In a study involving U.S., Filipino, Indian and Chinese business students, Morris and colleagues (1998) found that conflict management styles differed as a function of cultural values. Non-U.S. respondents preferred conflict avoidance more than U.S. respondents and U.S. respondents preferred a "competing" conflict style more than the others. These authors did test for mediation using the Baron and Kenny (1988) approach. They report that cultural values of social conservatism, self-enhancement, and openness to change. (Schwartz, 1994) and individualism versus collectivism (Triandis et al., 1986) mediated the relationship between participants' national culture and their preferred conflict management styles.

\section{Critique of the Individual Level or Entity/trait Approach}

There is surprisingly little published negotiation research using this individuallevel conceptualization. The reason seems to be that cultural values measured at the individual level do not predict behavior very well (Morris \& Fu, 2001; Kitayama, 2002). Some of the failure of this conceptual approach may be due to the difficulties in measuring cultural values; after all personality traits do not do a good job of predicting behavior either (Heine, Lehman, Peng, \& Greenholtz, 2002). However, a more fundamental explanation is that this individual-level conceptualization of culture is simply wrong. Culture is a group-level construct. It captures the central tendency among a group of people and it explains differences between groups of people. Culture is not an individual-level construct. Treating it as such and using it at the individual level to predict behavior violates its fundamental conceptualization. The fact that individual 
differences in cultural values have not been shown to predict individual differences in negotiation behaviors suggests strongly that the individual-level conceptualization of culture violates assumptions of theoretical isomorphism across levels (Klein \& Kozlowski, 2000).

\section{The Cultural Group Approach}

Some research on culture and negotiation conceptualizes culture at the group level, usually using national cultural designations from prior research on cultural values (Hofstede, 1980; Schwartz 1994; see also Peterson \& Smith, Chapter 2) and norms (e.g., communication strategies, Hall, 1977) to describe the group. Taking a group-level perspective is consistent with the theoretical definition of culture and does not violate any assumptions of isomorphism across levels. This research hypothesizes differences in negotiation strategy and outcomes based on cultural prototypes (central tendencies) on values, norms, beliefs, as well as the ideology of cultural social, political, and economic institutions. Thus, this research takes a cultural profile approach and does not limit the description of culture to a single dimension.

This research usually measures cultural values at the individual level, but not for the purpose of using them as individual-level predictors. Instead individual-level values are aggregated and used for what is called a sampling check (Brett, Tinsley, Janssens, Barsness, \& Lytle, 1997). A sampling check demonstrates that cultural group members in the study do reflect the values, norms, beliefs that prior research has documented as descriptive of that culture. These values, norms, and beliefs are used as explanations within hypotheses. Research taking the cultural group approach has studied cognitive processes related to negotiation, norms, use of strategy in dispute resolution and deal 
making, and outcomes.

Negotiator cognitions. Group-level research has documented cultural variation in cognitive processes related to negotiations. For instance, Gelfand, Nishi, Holcomb, Dyer, Ohbuchi, \& Fukuno (2001) found cultural differences in cognitive representations of conflict between Japanese and U.S. students. The authors used multidimensional scaling (MDS), which enabled them to locate stimuli (here, conflict episodes) in a spatial configuration which demonstrated the underlying dimensions of construal that participants used to represent the stimuli. According to Gelfand et al. (2001), although there were universal conflict dimensions, such as viewing conflict through the compromise versus win frame, U.S. and Japanese participants differed in how they applied this frame. Citing previous research, the authors suggested that the Japanese participants would be more likely to perceive conflicts as compromise-focused due to the cultural importance of harmony and the notion that the person is inseparable from the conflict. As predicted, when Japanese participants and U.S. participants were given the same sets of conflicts, Japanese participants were more likely to perceive these sets of conflicts as compromise-focused than were U.S. participants. In other words, the Japanese participants were more predisposed to perceive mutual blame and the need for compromise than were U. S. participants.

In another set of studies of cognitive biases, researchers found that egocentric perceptions of fairness (i.e. the self-serving bias) were more prevalent among disputants from an individualistic culture (U.S.) than a more collectivist culture (Japan), (Gelfand, Higgins, Nishii, Raver, Dominguez, Murakami, Yamaguchi, Murakami, \& Toyama, 2002). In four separate studies, the researchers demonstrated that U.S. participants were 
more likely to fall prey to egocentric perceptions of fairness than were Japanese participants. For instance, prior to negotiation, U.S. participants were more likely than Japanese participants to believe that they would be fairer than their counterparts. In addition, independent self-construals (or viewing oneself as independent from others, typically associated with individualist cultures) were significantly related to egocentric perceptions of fairness. U.S. negotiators were also more accepting of feedback when it was self-serving than when it was self-damaging, a process that was reversed among Japanese participants. The cultural explanation for these findings was that in individualistic cultures, like the U.S., the self is served by enhancing one's own positive attributes, while in collectivist cultures, like Japan, the self is served by blending in and maintaining interdependence with others.

Negotiation Norms. In research analyzing negotiators' norms (appropriate behavior), Tinsley and Pillutla (1998) proposed that cultural differences in individualism/collectivism would account for differences in negotiators' self-interest and cooperative behavior. They showed that U.S. negotiators were more individualistic and Hong Kong Chinese negotiators were more collectivistic. They predicted and found that U.S. negotiators rated self-interested behavior and joint problem-solving as more appropriate than Hong Kong negotiators. They also found behavioral differences in how U.S. and Hong Kong negotiators interpreted the researchers' instructions that were consistent with participants' differences in individualism/collectivism. The U.S. participants interpreted cooperative instructions as meaning they should strive for joint gain; Hong Kong participants interpreted the same instructions to mean they should make equality their goal. 
Negotiation Outcomes. There have been a series of studies of cultural group and negotiators' outcomes. Most of these studies focus on joint gains or integrative outcomes. Some incorporate analysis of negotiators' strategies based on analysis of transcripts of the negotiations. In the first of this series, Brett and Okumura (1998) generated hypotheses about Japanese and U.S. negotiators' scripts and schemas based on the collectivist-individualist and the hierarchical-egalitarian dimensions of national culture (Schwartz, 1994). They collected data from 30 Japanese-U.S. intercultural, 47 U.S.-U.S. intra-cultural, and 18 Japanese-Japanese intra-cultural negotiation dyads. Their major hypothesis was that cultural differences would cause joint gains to be lower in intercultural dyads than either set of intra-cultural dyads. They found that there was less understanding of the other parties' priorities in inter- than in intra-cultural negotiations, and that inter-cultural negotiators were less able to use information about priorities to generate joint gains than were their intra-cultural counterparts. In addition to difficulties in information exchange, Brett and Okumura found, consistent with predictions about differences in hierarchical cultural values, that Japanese participants did not value BATNA (or best alternative to a negotiated agreement) alternatives (Fisher, Ury \& Patton, 1991) as a source of power in negotiations in the same way U.S. participants did, and they proposed that this difference may have contributed to the low level of joint gains in the intercultural dyads. Finally, differences in U.S. and Japanese negotiators' views of self-interest may have further hampered the ability of intercultural dyads to create joint gains, since the individualistic U.S. negotiators showed stronger self-interest than the more collectivistic Japanese negotiators. This may have led to a goal mismatch, causing negotiators to end negotiations prematurely, thus creating lower joint gains as a dyad. 
Another study of inter and intra-cultural dyads negotiating an integrative task, which also used national culture to generate hypotheses is Natlandsmyr and Rognes' (1995) study of Mexican and Norwegian negotiators. There were 12 Mexican dyads, 12 Norwegian dyads, and 6 cross-cultural dyads in this study.

Natlandsmyr and Rognes (1995) developed and tested competing hypotheses as to whether Mexican or Norwegian dyads would achieve more integrative outcomes. They noted that Mexico's cultural profile, according to Hofstede (1980) was high masculinity, high uncertainty avoidance, high power distance, and relatively low individualism. In contrast, Norway's cultural profile was characterized as a feminine, with weak uncertainty avoidance, low power distance, and moderately high individualism. Citing research indicating collectivists might be more inclined to strive for mutually beneficial agreements, the authors hypothesized that Mexicans might achieve higher integrative outcomes than Norwegians. Alternatively, they proposed that Norwegians might achieve higher integrative outcomes than Mexicans. Their reasoning was that the Mexicans' competitiveness and assertiveness typified by masculine culture and uncertainty avoidance could cause them to focus more on the competitive and positional aspects of the negotiation and hinder the exchange of information on interests and the development of creative proposals. Natlandsmyr and Rognes (1995) also predicted that the intercultural dyads would perform at the level of the poorest performing intra-cultural dyads, citing the difficulty of communicating across cultural boundaries.

In this study, the Norwegians achieved higher integrative outcomes than Mexicans and the intercultural dyads performed at the level of the Mexican intra-cultural dyads. An analysis of negotiation transcripts showed differences in how the negotiations 
proceeded in the two cultures. The Norwegian intra-cultural negotiations had distinct stages - an initial distributive phase, an integrative phase, and a final adjustment phase. Mexican intra-cultural negotiations, however, had no distinct stages; distributive behavior lasted throughout the negotiation.

Negotiation strategy. In a study of the strategies used to resolve disputes, Tinsley (1998) based hypotheses about expected differences between U.S., German, and Japanese dispute resolvers on the dimensions of individualism/collectivism and hierarchy/egalitarianism. She found that German and U.S. dispute resolvers, who as a group were higher on individualism than Japanese dispute resolvers, used interest-based strategies more than the Japanese. In contrast, the Japanese, who as a group were lower on individualism and higher on hierarchy than U.S. or German participants, used power strategies more than the German or the U.S. dispute resolvers.

In a related study Tinsley and Brett (2001) hypothesized cultural differences in discussing interests, in synthesizing multiple interests, and reaching integrative agreements based on differences between Hong Kong and U.S. dispute resolvers with respect to self-direction, hierarchy, and tradition. The U.S. dispute resolvers were more self directed and less hierarchical and tradition bound than the Hong Kong dispute resolvers. These cultural differences were reflected in the U.S. dispute resolvers' greater emphasis on discussing interests and synthesizing multiple interests, and their more integrative agreements than the Hong Kong dispute resolvers.

Communication styles in negotiation. Three studies have elaborated on the implications of high versus low context communication styles in cultures for deal making negotiations. This cultural dimension, first labeled by Hall (1976), distinguishes between 
high-context national cultures (such as Japan and Russia) where people tend to communicate indirectly and low-context cultures, such as the U.S. and Israel where people tend to communicate directly. In high context cultures, people understand each other because they read meaning from the social context in which the message is delivered. By contrast, people in low-context cultures understand each other because they share a vocabulary. They do not need to read meaning from the social context in which the message is delivered.

In this series of studies, negotiators from high and low context cultures demonstrated that they gained information about each other's preferences and priorities in different ways. In the high context cultures, negotiators inferred each other's priorities indirectly via the pattern of proposals and counter proposals in their negotiation. In low context cultures, negotiators understood each other's priorities directly using a process of questions and answers. Negotiators who performed their culturally consistent information gathering strategy well generated equally high joint gains.

In the first of these studies, Adair, Okumura, and Brett (2001) compared negotiation behavior of U.S. and Japanese negotiators in both inter- and intra-cultural dyads using negotiation transcripts. In the intra-cultural context, the authors found that U.S. negotiators relied more on direct information sharing than their Japanese counterparts did. In contrast, Japanese negotiators tended to use indirect information sharing to gain information about the other parties' preferences and priorities, through inferring preferences and priorities from the pattern of proposals and counter proposals. According to Adair et al., in inter-cultural negotiations, Japanese negotiators tended to adapt to the U.S. negotiators' style of direct information sharing. Despite this adaptation, 
however, inter-cultural dyads achieved lower joint gains than intra-cultural dyads. The authors suggested that this deficit might be due to an inability for inter-cultural negotiators to adapt successfully. Specifically, U.S. negotiators did not understand the priorities of Japanese negotiators, and the U.S. negotiators were unsuccessful in their attempts to get Japanese negotiators to discuss negotiation procedures.

Adair and Brett (2005) generalized this finding in several ways. First, their study included 102 high-context dyads from Russia, Japan, Hong Kong, and Thailand; 89 low context dyads from Germany, Israel, Sweden, and the US; and 45 mixed high/low context dyads from the US and Hong Kong, and the US and Japan. The researchers audio taped, transcribed, and coded transcripts of the negotiations as well as recording negotiation outcomes. Each transcript was then divided into quarters based on the number of speaking turns in each quarter. Finally, the authors measured sequences of behavior. For example, a reciprocal sequence would be when negotiator A used direct information sharing and negotiator $\mathrm{B}$ responded with direct information sharing. A complementary sequence would be if negotiator A used direct information sharing and negotiator B responded with indirect information sharing. The authors then tested hypotheses about at what stage of the negotiation, negotiators from high versus low context cultures would engage in what type of communication sequence.

There are many interesting findings in this paper, however, we focus on those related to information sharing and outcomes. Negotiators from low context cultures engaged in more reciprocal, direct information sharing sequences ( $Q$ \& $A)$ than negotiators from high context cultures throughout all four stages of the negotiation. Negotiators from high context cultures engaged in more reciprocal indirect information 
sharing (offers) throughout the first 3 quarters of the negotiation than negotiators from low context cultures. Negotiators from low context cultures caught up in terms of making offers in the fourth quarter. Regardless of using direct or indirect information sharing sequences, negotiators who got information sharing going during the first half of the negotiation had higher joint gains than those who did not.

The mixed context negotiators' information sharing pattern was direct, like that of the low context negotiators. However, the mixed context negotiators did not seem to be able to transform the information they collected via direct information sharing into offers and their joint gains lagged. This finding suggests that when low context negotiators are using offers they are doing so for a somewhat different purpose than when high context negotiators are using offers (at least the way that high context negotiators use offers in the first half of the negotiation). It appears that low context negotiators first use direct information sharing to get information and then use that information to construct offers. The authors did not report on national cultural differences within the high or low contact classifications. Had these differences been large, however, they would have swamped the between context differences.

Adair, Weingart, and Brett (in press) investigated these ideas further. They proposed that early first offers are culturally normative in Japan as a means to begin information sharing and are used to gain the information needed to generate joint gains. In contrast, they proposed that in the U.S. early first offers would have an anchoring effect that would hinder the negotiation of joint gains. Using data from the negotiation transcripts of 20 U.S. and 20 Japanese dyads, results supported two hypothesized interactions: 1) early offers generated higher joint gains for Japanese and lower joint 
gains for U.S. negotiators; 2) exchanging information prior to the first offer generated higher joint gains for U.S. and lower joint gains for Japanese negotiators. Additional analyses supported their predictions that early offer patterns represented information gathering in Japanese negotiations and information consolidation in U.S. negotiations.

The results of these three studies of high/low context cultural communication patterns contribute to theories of negotiation and culture by showing that the use and efficacy of early offers and information exchange differs across cultural groups in ways that systematically reflect cultural differences in communication.

The group-level approach to studying culture and negotiation has generated a variety of insights. Cultural dimensions, like individualism versus collectivism, Schwartz's (1994) egalitarianism versus hierarchy (Hofstede's power distance), and high versus low context communication predict important cultural group differences related to negotiation with respect of cognitive biases, norms, behaviors, and outcomes.

Negotiators from Western cultures are generally more individualistic and less hierarchical and tradition bound and more direct than negotiators from East Asian cultures. This pattern of cultural differences is reflected in the different ways that people from these different cultures negotiate.

\section{Critique of the Cultural Group Approach}

The cultural group level approach, unlike the individual level approach correctly conceptualizes culture. Yet, this approach, too, is not without its conceptual flaws. A major critique is that researchers use cultural patterns to generate hypotheses but do not directly test mechanisms. Thus, within a study, this approach fails to demonstrate direct empirical connections between cultural values and behavior (see for this critique, 
Oyserman, Coon, \& Kemmelmeier, 2002). Another problem with the cultural group level approach is that the sampling check suffers from all the methodological problems that threaten the validity of individual-level measures of cultural values. For example, if cultural variations in response style are not controlled (see Leung, Chapter 4 for a discussion of proper controls), sampling check results may not validate the sample. Yet, another problem plaguing management research using this group level approach is that managers are highly self selected in some cultural groups. Consider a national culture like China that is still fundamentally agrarian and categorized as collectivist by Hofstede (2001). Managers in China, especially those in the public sector may be quite collectivist; however, those who have self selected into the private sector and are working for multinational organizations, are not likely to be collectivist in terms of placing the value of the public good above the value of the good for the private enterprise. This highlights the fact that national cultures are not unitary and the cultural group level approach tends to treat them as so. Within-culture variation will reduce the power of hypotheses derived at the cultural group level. This major critique of the cultural group approach is the strength of the dynamic constructivist approach which is the subject of the next section.

\section{The Dynamic Constructivist Approach}

The dynamic constructivist approach to studying culture differs from the cultural dimension approach in two important ways. First, it recognizes that cultures are not unitary; that many cultures encompass basic tensions between contradictory values, norms, even ideologies. Second, it recognizes that people use knowledge structures to interpret events and direct behavior. The knowledge structure perspective emphasizes 
that people have stores of many different knowledge structures, some of which are shared with other members of their culture. Since culture is a functional solution that grows out of the patterned ways that people in a group respond to the fundamental problems of social interaction (Smith et al., 1996) the knowledge structure (how to interpret, how to act) that is linked to a particular problem of social interaction like negotiation may vary from culture to culture. For example, Morris and Peng (1994) found that when interpreting others' behaviors, people from Western national cultures were generally more likely to make dispositional attributions, whereas East Asians were generally more likely to make situational attributions. Third, use of knowledge structures is dynamic depending on accessibility, availability, and activation (Morris \& Fu, 2001).

The dynamic constructivist perspective suggests that behavior within the same culture will be dynamic, that is, different for different people from within the same culture, depending on the context (Gelfand \& Cai, 2004). Referencing the work of culturalists such as Geertz (1975) and Kroeber \& Kluckhohn (1963), Kitayama (2002) noted that local practices, relationships, and social and political institutions affect how people come to think, act, and feel with reference to these local practices, relationships, and institutions. The social context, therefore, may prompt negotiators to use different knowledge structures, and thus different cognitions, motivations, and behaviors even within the same culture. The idea of context cuing cognitions that elicit different behaviors is the principal idea behind the dynamic constructivist perspective.

Recently negotiation researchers have begun work in the dynamic constructivist perspective, although much of the research taking this approach lies outside the realm of negotiations (see, e.g., Knowles, Morris, Chiu, \& Hong, 2001; Brett \& Gelfand, 2006 ). 
In one example, Gelfand and Realo (1999) explored how cultural values moderated the effect of accountability on negotiators' psychological states, behaviors, and outcomes. Typically, researchers find that accountability pressure, or having to answer to constituents for their behavior, makes negotiators behave more competitively, and this contentious behavior makes it harder to reach agreement in inter-group negotiations (Pruitt \& Carnevale, 1993). Gelfand and Realo (1999) conducted two laboratory studies. In the first study, they used a sample of 102 U.S. students, with 36 of these students being of Asian background. The second study utilized Estonian students and U.S. students. In both studies, researchers manipulated accountability (high or low) and measured both negotiation behavior and participants' cultural values. Consistent with previous findings, U.S. participants with Western backgrounds scored higher on individualism and lower on collectivism (as measured by the Triandis (1994) individualism-collectivism scale) than did both U.S. participants from Asian background and Estonian participants. In contrast to prior research, accountability did not necessarily produce competitive behavior. Instead, Gelfand and Realo found that accountability produced the behavior most culturally normative for the individuals in question. Specifically, high accountability pressure led to competitive behavior for those negotiators who scored high in individualism, but to cooperative behavior in those negotiators who scored high in collectivism.

In another demonstration of the dynamic constructivist perspective, Fu, Morris, Lee, Chao, Chiu, \& Hong (forthcoming) showed that individual differences in need for closure (NFC) interacted with cultural group variables to determine East Asian versus Western differences in conflict style and procedural preferences, information gathering in 
disputes, and fairness judgments in reward allocations. They demonstrated that NFC, an individual difference measure, moderated the tendency for individuals to engage in culturally prototypical behavior. In other words, individuals with high NFC were more likely to adhere to cultural convention. According to Fu et al., high NFC individuals are motivated to adhere to cultural norms because they seek the epistemic security of consensual validation. Specifically, Fu et al. (2007) found in Study 1 that the greater tendency for U.S. participants to choose relationally unconnected third parties to manage disputes and of Chinese to choose relationally connected third parties was moderated by NFC, with high NFC leading to greater culturally-prototypical behavior in each group. In Study 2, the researchers found that NFC moderated the differential tendency for EuroAmericans to seek information relevant to investigative approaches and Asian-Americans to seek information relevant to concilitative approaches. In Study 3, Fu et al. found that NFC moderated the tendency of bicultural participants to favor equality-based allocations more when Chinese rather than American culture was primed and vice-versa for equitybased allocations.

A study of distributive negotiation outcomes showed that factors that predict these outcomes in US culture do not do so in Chinese culture. Barry \& Friedman (1998) showed that negotiators in the US who were extroverted and agreeable negotiated lower individual gains than negotiators who did not have these personality traits. Liu, Friedman, and Chi (2005) hypothesized that these findings would not generalize to Chinese culture because the Chinese are collectivist and therefore regardless of personality traits they are more socially engaged with the other party than negotiators from individualist cultures. They argued that whereas these personality traits may make Chinese more gregarious, 
they will not make them any more sensitive to the concerns of the other negotiator. They predicted and found an interaction between cultural group (US versus Chinese), personality characteristic, and individual outcomes (as well as precursors to individual outcomes such as opening offers and responses). These researchers then flipped the model, proposing that personality characteristics that are particularly Chinese, e.g. preference for harmony, face, and Ren Qing (belief that long-term relationships are important) would impact Chinese negotiators' individual outcomes, but not those of US negotiators. Their reasoning was that the social norms associated with these factors in U.S. culture are not sufficiently salient to make them relevant to distributive bargaining. This hypothesis, too, was supported. The data from this study support the constructivist perspective that factors that affect negotiation behavior and outcomes in one culture do not necessarily affect negotiation behavior and outcomes in another culture.

In a study of how peers versus superior managers intervene in employee disputes in China, Japan, and the US,, Brett, Tinsley, Shapiro, \& Okumura (in press) predicted that within Chinese culture the position of the third party (peer versus superior) would have a stronger impact on their party dispute intervention behavior (who made the decision and what was the decision to resolve the dispute) than within U.S. or Japanese culture. Their reasoning, grounded in references to Chinese historical and political events, was that cultural traditions in China, more so than in the U.S. or Japan value both authoritarian and egalitarian behaviors. They found that third party behaviors reported by the U.S. and Japanese managers reflected their cultures' prototypical values (i.e. a context-general modal response consistent with an entity/trait perspective), but Chinese managers' behaviors reflected contextual effects. Specifically, Chinese managers who 
were bosses tended to decide themselves how to resolve the conflict (who) and that decision often supported the status quo (what); Chinese managers who were peers tended to involve the disputants in making the decision to resolve the conflict (who) and that decision often involved change (what). Japanese managers tended to stick with the status quo; U.S. managers tended to make decisions that departed from the status quo.

These authors offer "cultural complexity theory" (CCT) to explain behavioral variation within and across cultures (Brett, et al., in press). CCT argues that in more complex cultures, people's behavior will be more labile and context dependent than in less complex cultures, where there are less likely to be context associated differences in behavior.

In sum, the studies using the constructivist approach find three effects. First, cultural groups differ in the knowledge structures that cultural members rely on to interpret and act in negotiations (e.g., Fu et al., 2007 in relation to NFC, and Liu et al. 2005 in relation to personality variables). Second, some contextual factors can amplify cultural effects by producing the culturally normative behavior (e.g., Gelfand \& Realo, 1999). In Gelfand and Realo's (1999) study, for instance, the authors showed that in conditions of high accountability, collectivists were more cooperative, while individualists were more competitive. Third, contextual factors can cue dynamism in cultural effects (Brett et al., in press).

\section{Critique of the Dynamic Constructivist Perspective}

The dynamic constructivist approach is not without its critics, including those who write about it (Morris \& Fu, 2001; Morris \& Gelfand, 2004). First, there are measurement problems similar to those that plague the entity/trait perspective. Second, 
there is not much research taking a constructivist perspective, especially in the area of negotiations (Morris \& Fu, 2001; Morris \& Gelfand, 2004). Of course, this constructivist approach is a relatively new conceptualization of culture's effects. However, there is also a problem of lack of sufficient precision in the theory leading to difficulty in making predictions. The Brett et al. (in press) articulation of cultural complexity theory is a serious attempt to provide a template for determining when a variety of different normative knowledge structures are likely to coexist within a cultural group and be cued by contextual variables. The challenge for future research is in extending this constructivist perspective from being static, that is, allowing for variation between cultures to dynamic, that is, predicting variation within cultures.

\section{Unresolved Issues and Opportunities for Research}

The two different principal approaches to studying culture and negotiation that we have discussed leave unresolved the issues of how best to demonstrate a cultural effect in negotiation empirically, and what causes cultural versus other contextual effects to become salient.

As documented in this review, negotiation researchers use multiple methods to demonstrate effects. This makes cross-study comparisons difficult and prompts debate about the legitimacy of the alternative approaches. Though the cultural group approach has gained prominence, and the dynamic constructivist approach is generating research, some still favor methods, such as priming, that allow individual-level variables, rather than group-level properties to predict individual behavior (e.g. Oyserman et al., 2002). Oyserman et al. contend that priming cultural differences in the laboratory may offer methodological advantages over the cultural group method. Given that culture is 
inherently group-oriented, however - individuals do not have cultures and one cannot have a culture without an iterative process between individuals - attempts to force culture to the individual level for methodological soundness may be misguided. Although researchers gain insight into specific cultural dimensions when these dimensions are primed in a laboratory setting, culture includes a constellation of likely unquantifiable factors that one cannot capture with a simple priming manipulation of one cultural dimension.

Culture, in fact, may be a phenomenon that simply does not fit neatly into conventional methodological procedures and conventions. Though we can classify an individual as belonging to a particular cultural group, culture itself makes no sense at the individual level. A culture cannot exist, in fact, at the individual level, for its very definition requires that it be a shared construct among some group of people, although of course individuals retain and are motivated to act by the activation of culturally based knowledge structures. Given this methodological conundrum, using characteristics of cultural groups to explain group differences in behavior seems to be the only solution. Yet, at least in negotiation research, the task of generating data on negotiations in a sufficient number of cultural groups to test directly relationships between group prototypes (central tendencies) on a variety of cultural dimensions and group differences in negotiation behavior and outcomes is daunting. The disappointment of this course of action is the loss of all the rich within-culture variance. Yet, even within-culture variation might be captured and explained using a dynamic constructivism approach embedded in a multicultural multi-level model, for example, negotiation outcome data 
from dyads from different cultures, with individual, dyad, and cultural group level data to use to account for group differences in negotiation outcomes.

Beyond the disagreement about how to demonstrate a cultural effect lies the unresolved issue of establishing boundary conditions for the instances in which cultural effects become more salient than other contextual factors. Two approaches exist in this domain - one focusing on situational factors (see, e.g., Brett et al., 2007) and other focusing on individual differences (see, e.g., Fu et al. 2007). Both lines of research will broaden knowledge about when and how culture operates and will facilitate viewing culture as a dynamic, rather than static, construct. Future research on situational factors can determine the types of negotiations and other contextual effects that elicit different cultural responses. In addition, research into individual differences in the propensity to act in culturally typically ways (such as NFC) may offer insight into why culture appears to affect certain individuals' behaviors more than others. Cultural cognition, a construct we discuss in subsequent paragraphs may represent another individual difference that explains how people react to inter-cultural situations.

Culture and negotiation research has many opportunities for the future. First, cultural researchers should address all the hot new areas of negotiation research. We know a good deal about information sharing in negotiations and now in cross-cultural negotiations, but we know much less about influence, and even less about factors such as trust and emotion. Any topic that is challenging to study within a culture is even more fun to study across cultures.

One more idea we have is to link cultural intelligence to performance in intercultural negotiations. Recall that inter-cultural negotiation performance was poor in the 
studies reviewed here (Adair, Okumura \& Brett, 2001; Brett \& Okumura, 1998;

Natlandsmyr \& Rognes, 1995). Is it possible that intervening to increase negotiators' cultural intelligence will help them overcome the challenges of inter-cultural negotiations? Cultural cognition, measured at the individual level, refers to an individual's ability to perceive and adapt to cultural differences (see also Thomas \& Fitzsimmons, Chapter 12). In preliminary research, we have found that cultural cognition, a construct based on cultural intelligence predicts behavior in multicultural settings (Crotty \& Brett, 2006) suggesting that it may predict behavior in inter-cultural negotiations as well.

\section{Conclusion}

Regardless of the approach - dimensional at the individual or group level, or dynamic constructivist, there is both opportunity and need for further research on culture and negotiations. From international peace to international business, negotiating across cultural boundaries is a reality of modern life. Research offers the opportunity to do it better. 


\section{References}

Adair, W. L., \& Brett, J. M. (2005). The negotiation dance: Time, culture, and behavioral sequences in negotiation. Organizational Science, 16(1), 33-51.

Adair, W. L., Okumura, T., \& Brett, J. M. (2001). Negotiation behavior when cultures collide: The United States and Japan. Journal of Applied Psychology, 86, 371385.

Adair, W. L., Weingardt, L., \& Brett, J. M. (in press). The timing and function of offers in U.S. and Japanese negotiations. Journal of Applied Psychology.

Baron, R. \& Kenny, D. A. (1986). The moderator-mediator variable distinction in social psychological research: Conceptual, strategic, and statistical consideration. Journal of Personality and Social Psychology, 51, 1173-1182.

Barry, B., \& Friedman, R. (1998). Bargainer characteristics in distributive and integrative negotiation. Journal of Personality and Social Psychology, 74, 345-359.

Brett, J. M. (2001). Negotiating globally. San Francisco, CA: Jossey-Bass.

Brett, J. M., \& Gelfand, M. (2006). A cultural analysis of the underlying assumptions of negotiation theory. . In L. Thompson (Ed.), Negotiation theory and research. New York: Psychology Press.

Brett, J. M., \& Gelfand, M. (2006 ). A cultural analysis of the underlying assumptions of negotiation theory. . In L. Thompson (Ed.), Negotiation theory and research. (pp. 173 - 202). New York: Psychology Press.

Brett, J. M., \& Okumura, T. (1998). Inter- and intracultural negotiation: U.S. and Japanese negotiators Academy of Management Journal, 41, 495-510. 
Brett, J. M., Tinsley, C., Janssens, M., Barsness, Z. I., \& Lytle, A. L. (1997). New approaches to the study of culture in Industrial/Organizational psychology. In P. C. Earley \& M. Erez (Eds.), New Perspectives on International/Organizational Psychology (pp. 75-129). San Francisco: Jossey-Bass.

Brett, J. M., Tinsley, C. H., Shapiro, D. L., \& Okumura, T. (in press). Intervening in employee disputes: How and when will managers from China, Japan, and the U.S. act differently?

Crotty, S., \& Brett, J. M. (2006). Multiculturalism lives: Predicting fusion collaboration in teams, Academy of Management. Atlanta, GA.

Fang, T. (1999). Chinese business negotiating style. Thousand Oaks, CA: Sage Publications.

Fisher, R., Ury, W., \& Patton, B. (1991). Getting to yes: Negotiating agreement without giving in (2nd ed.). Boston, MA: Houghton Mifflin.

Fu, H., Morris, M. W., Lee, S., Chao, M., Chiu, C., \& Hong, H. (forthcoming). Epistemic motives and cultural conformity: Need for closure, culture, and context as determinants of conflict judgments. Journal of Personality and Social Psychology.

Gabrielidis, C., Stephan, W. G., Ybarra, O., Dos Santos Pearson, V., \& Villareal, L. (1997). Preferred styles of conflict resolution: Mexico and the U.S. Journal of Cross-cultural Psychology, 28, 661-677.

Geertz, C. (1975). On the nature of anthropological understanding. American Scientist, $63,47-53$. 
Gelfand, M., \& Cai, D. A. (2004). Cultural structuring of the social context of negotiation. In M. Gelfand \& J. M. Brett (Eds.), Handbook of negotiation and culture. (pp. 238 - 257). Palo Alto, CA: Stanford University Press.

Gelfand, M., \& Realo, A. (1999 ). Individualism-collectivism and accountability in intergroup negotiations. Journal of Applied Psychology, 84, 721-736.

Gelfand, M. J., Higgins, M., Nishii, L. H., Raver, J. L., Dominguez, A., Murakami, F., et al. (2002). Culture and egocentric perceptions of fairness in conflict and negotiation. Journal of Applied Psychology, 87, 833-856.

Gelfand, M. J., Nishii, L. H., Holcombe, K. M., Dyer, N., Ohbuchi, K., \& Fukuno, M. (2001). Cultural influences on cognitive representations of conflict: Interpretations of conflict episodes in the United States and Japan. Journal of Applied Psychology, 86, 1059-1074.

Graham, J. (1985). The influence of culture on business negotiations Journal of International Business Studies, 16, 81-99.

Hall, E. (1977). Beyond culture. Garden City, NY: Anchor Press.

Heine, S. J., Lehman, D. R., Peng, K., \& Greenholtz, J. (2002). What is wrong with cross-cultural comparisons of subjective Likert scales? The reference group effect. Journal of Personality and Social Psychology, 82, 903-918.

Hofstede, G. (1980). Culture's consequences: international differences in work related values. Beverly Hills, CA: Sage.

Hofstede, G. (2001). Culture's consequences: Comparing values, behaviors, institutions and organizations across nations ( 2 nd ed.). Thousand Oaks, CA: Sage Publications. 
Hui, C. H. (1984). Individualism-collectivism: Theory, measurement and its relation to reward allocation: University of Illinois, Urbana-Champaign.

Kitayama, S. (2002). Culture and basic psychological processes: Toward a system view of culture. Psychological Bulletin, 128, 89-96.

Klein, K. J., \& Kozlowski, S. W. (2000). From micro to meso: Critical steps in conceptualizing and conducting multilevel research. Organizational Research Methods, 3(3), 211-236.

Knowles, E., Morris, M., Chiu, C., \& Hong, Y. (2001). Culture and the process of person perception: Evidence for automaticity among East Asians in correcting for situational influences on behavior. Personality and Social Psychology Bulletin, 27, 1344-1356.

Kroeber, A., \& Kluckhohn, C. (1963). Culture: A critical view of concepts and definitions. New York: Knopf.

Leung, K. (1988). Some determinants of conflict avoidance. Journal of Cross-cultural Psychology, 19, 125-136.

Lytle, A. L., Brett, J. M., Barsness, Z. I., Tinsley, C. H., \& Janssens, M. (1995). A paradigm for confirmatory cross-cultural research in organizational behavior. Research in Organizational Behavior, 17, 167-214.

March, R. M. (1988). The Japanese negotiator. Tokyo, Japan: Kodansha International. Morris, M., Williams, K., Leung, K., Larrick, R., Mendoza, T., Bhatnagar, D., Li, J., Kondo, M., Luo, J., \& Hu, J. (1998). Conflict management style: Accounting for cross-national differences. Journal of International Business Studies, 29, 729747. 
Morris, M., \& Fu, H. (2001). How does culture influence conflict resolution? A dynamic constructivist analysis. Social Cognition, 19, 324-349.

Morris, M. W., \& Gelfand, M. (2004). Cultural differences and cognitive dynamics:

Expanding the cognitive perspective on negotiation. In M. Gelfand \& J. M. Brett (Eds.), The Handbook of negotiation and culture. (pp.45-70). Palo Alto, CA: Stanford University Press.

Morris, M. W., \& Peng, K. (1994). Culture and cause: American and Chinese attributions for social and physical events. Journal of Personality and Social Psychology, 67, 949-971.

Natlandsmyr, J. H., \& Rognes, J. (1995). Culture, behavior, and negotiation outcomes: A comparative and cross-cultural study of Mexican and Norwegian negotiators. International Journal of Conflict Management, 6(1), 5-29.

Pruitt, D. G., \& Carnevale, P. J. (1993). Negotiation in social conflict. Buckingham, UK: Open University Press.

Schwartz, S. (1994). Beyond individualism/collectivism: New cultural dimensions of values. In H.C. Triandis, U. Kim, \& G. Yoon (Eds.), Individualism and collectivism. (pp.85 - 117). London: Sage

Smith, P. B., Dugan, S., \& Trompenaars, F. (1996). National culture and the values of organizational employees: A dimensional analysis across 43 nations. Journal of Cross-cultural Psychology, 27, 231-264.

Tinsley, C. (1998). Models of conflict resolution in Japanese, German, and American cultures. Journal of Applied Psychology, 83, 316-323. 
Tinsley, C. H., \& Brett, J. M. (2001). Managing workplace conflict in the United States and Hong Kong. Organizational Behavior and Human Decision Processes, 85, 360-381. 